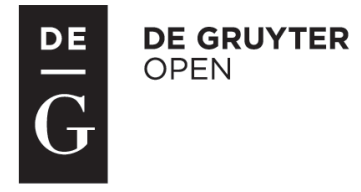

\title{
THE EFFECTS OF DIETARY CINNAMON (CINNAMOMUM ZEYLANICUM) OIL SUPPLEMENTATION ON BROILER FEEDING BEHAVIOUR, GROWTH PERFORMANCE, CARCASS TRAITS AND MEAT QUALITY CHARACTERISTICS*
}

\author{
George K. Symeon ${ }^{1}$, Anastasios Athanasiou ${ }^{1}$, Nikos Lykos ${ }^{1}$, Maria A. Charismiadou', \\ Michael Goliomytis ${ }^{1}$, Nikos Demiris ${ }^{2}$, Anna Ayoutanti ${ }^{1}$, Panagiotis E. Simitzis ${ }^{1 *}$, \\ Stelios G. Deligeorgis ${ }^{1}$
}

\begin{abstract}
${ }^{1}$ Department of Animal Breeding and Husbandry, Faculty of Animal Science and Aquaculture, Agricultural University of Athens, 75 Iera Odos, 11855 Athens, Greece

${ }^{2}$ Department of Statistics, Athens University of Economics and Business, 76 Patission Street, 10434 Athens, Greece •Corresponding author: pansimitzis@aua.gr
\end{abstract}

\begin{abstract}
The aim of this study was to investigate the effects of dietary supplementation with cinnamon oil on growth performance, behaviour, carcass traits and meat quality of broilers. One hundred and thirty-five Cobb 700 day-old broiler chickens were randomly assigned into three equal treatment groups with three replicates (pens) of fifteen chickens each. The dietary treatments consisted of the basal diet as control (C) and basal diet supplemented with 0.5 (C1) or 1.0 (C2) $\mathrm{ml}$ of cinnamon oil per $\mathrm{kg}$ of feed. On day 49,5 birds from each pen (15 per treatment) were slaughtered and the pectoralis major muscle samples were collected for meat quality evaluation. No effect of cinnamon oil supplementation on the probability of a bird standing at the feeder or the drinker was observed until the age of 17 days. Moreover, cinnamon oil supplementation did not affect body weight, feed intake and feed conversion ratio. No significant differences were also found in internal organs' weights and carcass characteristics among the treatments, although cold carcass weight was the lightest in the $\mathrm{Cl}$ group. At the same time, colour parameters, $\mathrm{pH}_{24}$, cooking loss, intramuscular fat and shear values were not affected by diets. The extent of lipid oxidation in raw pectoralis major muscle stored at $4^{\circ} \mathrm{C}$ for up to 9 days or at $-20^{\circ} \mathrm{C}$ for up to 6 months was also not influenced by the dietary treatment. The present findings suggest that cinnamon oil at the selected concentrations may not have the potential to improve broiler growth performance, carcass and meat quality characteristics.
\end{abstract}

Key words: cinnamon, broiler, performance, meat quality, behaviour

Broiler meat has many desirable nutritional characteristics, such as low intramuscular fat content and relatively high concentrations of polyunsaturated fatty acids (PUFAs). However, increasing the degree of unsaturation of muscle membranes by

\footnotetext{
*This research project was funded by the Hellenic State.
} 
dietary manipulation increases the susceptibility of poultry meat to oxidative deterioration (Engberg et al., 1996). Oxidation by free radicals is one of the primary mechanisms of quality deterioration in foods and especially in meat products. It is initiated in the highly-unsaturated fatty acid fraction of membrane phospholipids, leading to the production of hydroperoxides, which are susceptible to further oxidation or decomposition to secondary reaction products such as short-chain aldehydes, ketones and other oxygenated compounds. These compounds may adversely affect lipids, pigments, proteins, carbohydrates, vitamins and the overall quality of products by causing loss of flavour, colour and nutritive value and limiting shelf life (Kanner, 1994).

Considerable interest has recently arisen in the use of natural products that would serve as alternatives to synthetic compounds aiming to improve meat quality, without leaving residues in the product or the environment. The use of natural antioxidants can extend the shelf life and increase the acceptability of chicken meat by the consumers (Fellenberg and Speisky, 2006). Furthermore, nutritional approaches (in vivo) are often more effective than direct post mortem addition (in vitro) of the antioxidant to the muscle because the compound is deposited where it is most needed. Antioxidant supplementation allows its incorporation into the subcellular membranes where it can effectively inhibit the oxidative reactions at their localized sites and improve meat quality due to delayed lipid oxidation and muscle discoloration (Govaris et al., 2004).

Cinnamomum zeylanicum Blume (Lauracae) is a tropical tree that grows wild mainly in Sri Lanka, but also in Madagascar, India and Indochina (Bakkali et al., 2008). The main compounds of cinnamon oil are cinnamaldehyde, benzaldehyde, limonene, linalool and eugenol (Baratta et al., 1998); the major constituent of cinnamon bark oil is cinnamaldehyde and, on the other hand, cinnamon leaf is rich in eugenol (Ranasinghe et al., 2002). It has antioxidant properties and its action is mainly attributed to cinnamaldehyde and eugenol, substances that react with lipid and hydroxyl radicals converting them into stable products through their hydrogendonating ability (Jayaprakasha et al., 2007). In detail, components of cinnamon oil appear to intercept the free radical chain of oxidation and donate hydrogen from the phenolic hydroxyl groups, thereby forming a stable end-product which does not initiate or propagate further oxidation of lipid (Jayaprakasha et al., 2004).

Scarce data exist regarding the influence of cinnamon oil incorporation in diet of broilers on the oxidative stability of derived meat. The objective of this study was to determine the effect of cinnamon (Cinnamomum zeylanicum) oil supplementation on meat oxidative stability as well as on feeding behaviour, growth performance, carcass traits and meat quality characteristics of broilers.

\section{Material and methods}

\section{Animals and diets}

One hundred and thirty-five Cobb 700 day-old broiler chickens, purchased from a local commercial hatchery, were weighed and randomly assigned into three equal 
treatment groups with three replicates (pens) of fifteen chickens each. One of the groups was the control (C) and was given basal diets, whereas the other two groups were given the same diets further supplemented with cinnamon oil at $0.5 \mathrm{ml} / \mathrm{kg}$ feed (C1), or at $1.0 \mathrm{ml} / \mathrm{kg}$ feed (C2). Concentration levels of cinnamon oil were chosen based on the existing literature.

Table 1. Composition and calculated analysis of the control diet

\begin{tabular}{l|c|c}
\hline & $\begin{array}{c}\text { Starter } \\
(1-22 \mathrm{~d})\end{array}$ & $\begin{array}{c}\text { Finisher } \\
(23-48 \mathrm{~d})\end{array}$ \\
\hline Composition (\%) & & \\
maize & 43.2 & 52.7 \\
soybean meal (44\% protein) & 31.5 & 20.0 \\
wheat & 20.0 & 15.0 \\
wheat bran & - & 9.0 \\
soybean oil & 1.9 & - \\
salt (NaCl) & 0.3 & 0.3 \\
dicalcium phosphate & - & 0.5 \\
limestone & 0.5 & 1.5 \\
vitamin and mineral premix & $2.5 *$ & $1.0^{* *}$ \\
Calculated analysis (\%) & & \\
dry matter - DM & 88.0 & 88.0 \\
digestible energy (MJ/ kg) & 12.5 & 11.7 \\
crude protein - CP & 20.0 & 18.0 \\
lysine & 1.2 & 0.9 \\
methionine and cystine & 0.8 & 0.6 \\
ash & 6.0 & 6.0 \\
fat & 5.0 & 3.5 \\
calcium & 0.8 & 1.0 \\
total phosphorus & 0.7 & 0.6 \\
\hline
\end{tabular}

${ }^{*}$ Premix contained per kg: $2.6 \mathrm{~g} \mathrm{Mn}, 1.4 \mathrm{~g} \mathrm{Fe}, 0.2 \mathrm{~g} \mathrm{Cu}, 1.5 \mathrm{~g} \mathrm{Zn}, 7 \mathrm{mg} \mathrm{Se}, 28 \mathrm{mg}$ Co, 28 mg I, $100.8 \mathrm{mg}$ retinol (vitamin A), $2.1 \mathrm{mg}$ cholecalciferol (vitamin $\mathrm{D}_{3}$ ), $0.42 \mathrm{~g}$ tocopherol (vitamin $\mathrm{E}$ ), $56 \mathrm{mg}$ menadione (vitamin $\mathrm{K}$ ), $42 \mathrm{mg}$ thiamine (vitamin $\mathrm{B}_{1}$ ), $140 \mathrm{mg}$ riboflavin (vitamin $\mathrm{B}_{2}$ ), $1.18 \mathrm{~g}$ niacin (vitamin $\mathrm{B}_{3}$ ), $14 \mathrm{~g}$ phytase and $14 \mathrm{~g}$ choline.

${ }^{* *}$ Premix contained per kg: 7 g Mn, 5 g Fe, 0.8 g Cu, 5 g Zn, 20 mg Se, 100 mg I, 100 mg Co, 360 mg retinol (vitamin A), $7.5 \mathrm{mg}$ cholecalciferol (vitamin $\mathrm{D}_{3}$ ), $1 \mathrm{~g}$ tocopherol (vitamin E), $200 \mathrm{mg}$ menadione (vitamin $\mathrm{K}$ ), $150 \mathrm{mg}$ thiamine (vitamin $\mathrm{B}_{1}$ ), $500 \mathrm{mg}$ riboflavin (vitamin $\mathrm{B}_{2}$ ), $4.25 \mathrm{~g}$ niacin (vitamin $\mathrm{B}_{3}$ ) and $35 \mathrm{~g}$ choline.

Broilers of each group were kept in identical floor pens $\left(3 \mathrm{~m}^{2}\right)$, with the same orientation. Each pen contained one bell drinker and one feeder in the same location and the floor was cemented and covered with a $5 \mathrm{~cm}$-deep layer of fresh straw. Conventional husbandry procedures were employed throughout the experiment (light exposure programme: $0-1$ days: $24 \mathrm{~h}$; 2-7 days: $23 \mathrm{~h}$; 8-24 days: $15 \mathrm{~h}$; $25-42$ days: 18 h; 43 days: 19 h; 44 days: 20 h; 45 days: 21h; 46 days: 22 h; 47 days: 23 h; 48 days: $24 \mathrm{~h}$, according to the Cobb 700 broiler commercial management guide). Room temperature was maintained at $32 \pm 1^{\circ} \mathrm{C}$ during the first week of the study and gradually decreased to $24^{\circ} \mathrm{C}$ by the end of the third week. Mortality rates of broilers were recorded. 
The feeding programme consisted of a starter diet until 21 days of age and a finisher diet until the end of the experiment (49 days) (Table 1). Cinnamon oil used in the present study was purchased from Benforado D.S.A. (Athens, Greece). It was extracted from the leaves of Cinnamomum zeylanicum and was stored in a stainless sealed container, appropriate for volatile compounds (1 1). Cinnamon oil main components were (\%): eugenol (76.70), benzaldehyde (9.90), limonene (4.40) and cinnamaldehyde (1.30) (R.C. Treatt Ltd, Suffolk, UK). The preparation of cinnamon supplemented diets was carried out every 5 days, throughout the experimental period. In detail, feed was placed in a plastic container and was sprayed gradually with cinnamon oil $(0.5$ or $1 \mathrm{ml} / \mathrm{kg})$. Feed was continuously mixed during spraying, with the intention to obtain a uniform distribution. After the application of the essential oil, container was sealed firmly so as to minimize the evaporation of volatile compounds. The size of container was $0.125 \mathrm{~m}^{3}$ (length $\times$ width $\times$ height: $0.5 \mathrm{~m} \times$ $0.5 \mathrm{~m} \times 0.5 \mathrm{~m})$.

Feed and water were available ad libitum. Feed intake (FI) per pen and individual body weight $(\mathrm{BW})$ of broilers were recorded weekly to estimate the respective feed conversion ratio (FCR) values. Moreover, broilers' behaviour was recorded daily until the 17th day of their age, using three Panasonic PV120 video cameras fitted with a $3.6 \mathrm{~mm}$ lens. Each camera was placed in a fixed position in order to record behaviour patterns in each pen (1 pen randomly selected per treatment group). The recorded data were then stored in a digital video recorder equipped with a hard disk (TX168, Telexper Inc, USA). The number of birds standing over a feeder or a drinker with its head towards the trough was recorded, by using time-lapse photography, every ten minutes of an hour.

Finally, at day 49 of age, forty-five chickens (15 per treatment group) were stunned, slaughtered and weights of liver, heart, gizzard and abdominal fat were measured using an electronic precision balance. After overnight chilling, carcasses were weighed and trimmed for breast fillets by removing skin and bones. The right fillet was used for the estimation of meat quality parameters and the left one for lipid oxidation measurements. The methods used in the present experiment were in accordance with the national legislation and the guidelines of the Research Ethics Committee of the Department of Animal Science and Aquaculture of the Agricultural University of Athens.

\section{Meat quality evaluation}

Colour and $\mathrm{pH}_{24}$

Pectoralis major muscle tissue samples left exposed to the air at room temperature for $30 \mathrm{~min}$ and meat colour were measured ( 3 measurements per sample) using a Miniscan XE (HunterLab, Reston, USA) chromameter set on the L*, a*, b* system (Commission International de l'Eclairage, 1976). White and black tiles were used as standards. $\mathrm{pH}_{24}$ was measured using a Sentron $1001 \mathrm{pH}$ System (Roden, the Netherlands) model, with the electrode inserted into the right section of the pectoralis major muscle 24 hours after slaughter. The $\mathrm{pH}$ meter was calibrated at $\mathrm{pH} 4.0$ and 7.0 (Merck, Darmstadt, Germany), at ambient temperature. 
Shear force value and cooking loss

The right pectoralis major muscle was weighed, placed in plastic bag and cooked in a water bath at $85^{\circ} \mathrm{C}$ for $30 \mathrm{~min}$, left under running water for $15 \mathrm{~min}$ and then left equilibrating, at room temperature. The samples were weighed again, in order to estimate the percentage of cooking loss (\%). Shear force was evaluated, as described by Cason et al. (1997), on samples cut perpendicularly to the fibre direction using a Zwick Testing Machine Model Z2.5/TN1S (Zwick GmbH \& Co, Germany), equipped with a Warner-Bratzler shear. Peak force values in $\mathrm{N} / \mathrm{mm}^{2}$ were recorded.

\section{Measurement of intramuscular fat}

Intramuscular fat (IMF) was measured according to the method first described by Folch et al. (1957). Tissue samples were homogenized with 2:1 chloroform-methanol mixture to a final 20 -fold dilution, of the tissue volume of the sample. The crude extract was diluted $1 / 5$ of its volume with water and separated in two phases. The lower phase contained the tissue lipids.

\section{Measurement of lipid oxidation (MDA analysis)}

Lipid oxidation was assessed on the basis of the malondialdehyde (MDA) formed during storage, a secondary lipid oxidation product formed by hydrolysis of lipid hydroperoxides. In the present study, MDA concentration in pectoralis major muscle samples was determined by using a selective third-order derivative spectrophotometric method (Botsoglou et al., 1994) on days 1, 3, 6 and 9 and 4, 5 and 6 months after storage at $4^{\circ} \mathrm{C}$ and $-20^{\circ} \mathrm{C}$, respectively. Derivative versus conventional spectrophotometry was adopted because it offers improved sensitivity, specificity and reliability of the measurements, since it eliminates potential interferences from other reactive compounds.

\section{Statistical analysis}

Performance, carcass and meat quality data were analysed with the MIXED procedure of SAS software (SAS Institute, 2005), with cinnamon oil treatment as the fixed effect. MDA concentration was evaluated with a repeated measures model. MDA, shear force and liver percentage values were log transformed prior to statistical analysis in order to meet ANOVA requirements for normal distribution and homogeneity of variances. The Bonferroni adjustment was used for mean comparisons and the significance level was set at 0.05 . Means are presented as least square means \pm standard error.

Behavioural data were analysed using bivariate mixed effects logistic regression. We assumed that Mij Bin (ni, Pij), where Mij denotes the number of the birds standing over a feeder $(i=1)$, standing over a drinker $(j=2)$, ni the total number of birds in pen $\mathrm{i}$, Pij the probability of a random bird standing over a feeder or a drinker and Bin represents the binomial distribution.

The basic model was as follows:

$$
\operatorname{logit}(P i j k)=\mu+\alpha_{i}+\beta_{j}+\gamma_{k}
$$


where:

$\operatorname{logit}(p)$ is the $\log (\mathrm{p} /[1-\mathrm{p}])$ transformation,

$P_{i j k}$ is the probability of a chicken standing over a feeder or a drinker,

$\mu-$ the overall mean,

$\alpha_{i}$ - the effect of age,

$\beta_{j}$ - the effect of the time of the day,

$\gamma_{k}-$ the random effect.

We assumed different random effects for standing over a feeder or a drinker. In addition, random effects within treatment were also correlated in order to capture the potential dependence on the effects, in the birds' behaviour. Statistical analyses were performed using the WINBUGS 1.4.3 software (Bayesian inference using Gibbs Sampling, Lunn et al., 2000).

\section{Results}

\section{Growth performance}

There were no significant differences in the values of BW, FI and FCR $(\mathrm{P}>0.05)$ among the groups (Table 2). At the same time, the incorporation of cinnamon oil in diet of broilers appeared not to influence mortality rates (4.44, 6.67 and 4.44 in $\mathrm{C}$, $\mathrm{C} 1$ and $\mathrm{C} 2$ group, respectively).

Table 2. Effect of different levels of cinnamon oil dietary supplementation on growth performance parameters of broilers (least square means \pm standard error)

\begin{tabular}{l|c|c|c|c|c}
\hline & \multicolumn{3}{|c|}{$\begin{array}{c}\text { Cinnamon oil supplementation } \\
\text { (ml/kg feed) }\end{array}$} & $\begin{array}{c}\text { Pooled } \\
\text { S.E.M.* }\end{array}$ & $\begin{array}{c}\text { Significance level } \\
\text { (P-value) }\end{array}$ \\
\cline { 2 - 5 } & 0 & 0.5 & 1.0 & & 0.148 \\
\hline Final body weight (g) & 2818 & 2675 & 2524 & 67 & 0.507 \\
Cumulative feed intake (g) & 6307 & 6762 & 6222 & 323 & 0.508 \\
\hline
\end{tabular}

*Standard error of the means.

No significant differences were found among the treatment groups.

\section{Broilers' behaviour}

Pf (mean coefficient estimates $(95 \%$ confidence interval) of $1.661(0.747,2.286)$ vs $1.570(0.646,2.189)$ vs $1.320(0.406,1.926)$ for the Control, $\mathrm{C} 1$ and $\mathrm{C} 2$ group, respectively) and $\mathrm{Pw}$ (mean coefficient estimates (95\% confidence interval) of 4.884 $(3.212,6.258)$ vs $4.746(3.136,6.172)$ vs $6.610(2.993,6.040)$ for the Control, C1 and $\mathrm{C} 2$ group, respectively) probabilities were not influenced by the cinnamon oil supplementation (Table 3).

Moreover, both age and time of the day had a minor negative significant effect on Pw with a mean coefficient estimate of $-0.02869(-0.04091,-0.01643)$ and $-0.01444(-0.02193,0.00609)(95 \%$ confidence interval) for age and time of the 
day, respectively. On the other hand, Pf was positively correlated with age (mean coefficient estimate of 0.00789 with a $95 \%$ confidence interval between -0.00282 and 0.01780 ) but negatively with the time of the day (mean coefficient estimate of -0.1164 with a $95 \%$ confidence interval between -0.01800 and -0.00512 ). Pf was significantly correlated with $\mathrm{Pw}$ with a correlation coefficient of $0.1246(0.0773$, 01713) (95\% confidence interval).

Table 3. Estimates ( $95 \%$ confidence intervals) of cinnamon essential oil dietary supplementation effect on the probability of a chicken standing at the feeder $(\mathrm{Pf})$ or the drinker $(\mathrm{Pw})$

\begin{tabular}{l|c|c|c}
\hline \multirow{2}{*}{} & \multicolumn{3}{|c}{ Cinnamon oil supplementation $(\mathrm{ml} / \mathrm{kg}$ feed) } \\
\cline { 2 - 4 } & 0 & 0.5 & 1.0 \\
\hline $\mathrm{Pf}$ & 1.661 & 1.570 & 1.320 \\
& $(0.749,2.286)$ & $(0.646,2.189)$ & $(0.406,1.926)$ \\
$\mathrm{Pw}$ & 4.844 & 4.746 & 4.610 \\
& $(3.212,6.258)$ & $(3.136,6.172)$ & $(2.993,6.040)$ \\
\hline
\end{tabular}

No significant differences were found among the treatment groups.

\section{Internal organs (liver, heart, gizzard) and abdominal fat}

The different levels of cinnamon oil supplementation did not influence abdominal fat and internal organs' (liver, heart and gizzard) weight (g) among the broiler groups (Table 4).

Table 4. Effect of cinnamon oil dietary supplementation on weight $(\mathrm{g})$ of broiler internal organs at slaughter (least square means \pm standard error)

\begin{tabular}{l|c|c|c|c|c}
\hline & \multicolumn{2}{|c|}{ Cinnamon oil supplementation (ml/kg feed) } & Pooled & $\begin{array}{c}\text { Significance level } \\
\text { (P-value) }\end{array}$ \\
\cline { 2 - 4 } & 0 & 0.5 & 1.0 & S.E.M.* & 0.754 \\
\hline Liver & 52.2 & 49.8 & 50.0 & 2.3 & 0.821 \\
Heart & 14.2 & 15.2 & 14.7 & 1.1 & 0.325 \\
Gizzard & 33.1 & 29.7 & 29.8 & 1.6 & 0.297 \\
Abdominal fat & 37.8 & 28.0 & 35.8 & 4.1 & \\
\hline
\end{tabular}

*Standard error of the means.

No significant differences were found among the treatment groups.

\section{Carcass and meat quality characteristics}

Cold carcass of the control group appeared to weigh more compared to the $\mathrm{C} 1$ group of broilers $(\mathrm{P} \leq 0.05)$. However, cinnamon oil supplementation did not have a significant effect on the evaluated carcass traits (carcass yield, breast, leg, wing, back-neck) of broilers (Table 5). Moreover, pectoralis major muscle quality characteristics $\left(\mathrm{pH}_{24}\right.$, colour parameters, cooking loss and shear force value) were not significantly influenced by the dietary treatment (Table 6). No significant effects of cinnamon oil supplementation on total intramuscular lipids were also found (Table 6). At the same time, the extent of lipid oxidation in raw pectoralis major muscle stored at $4^{\circ} \mathrm{C}$ for up to 9 days or at $-20^{\circ} \mathrm{C}$ for up to 6 months varied with the storage time but not with the dietary treatment (Table 7). 
Table 5. Effect of cinnamon oil dietary supplementation on carcass characteristics of broilers (least square means \pm standard error)

\begin{tabular}{l|c|c|c|c|c}
\hline & \multicolumn{3}{|c|}{$\begin{array}{c}\text { Cinnamon oil supplementation } \\
\text { (ml/kg feed) }\end{array}$} & $\begin{array}{c}\text { Pooled } \\
\text { S.E.M.* }\end{array}$ & $\begin{array}{c}\text { Significance } \\
\text { level } \\
\text { (P-value) }\end{array}$ \\
\cline { 2 - 4 } & 0 & 0.5 & 1.0 & & 0.047 \\
Cold carcass weight (CCW) $(\mathrm{g})$ & $2056.6 \mathrm{a}$ & $1892.1 \mathrm{~b}$ & $1995.6 \mathrm{ab}$ & 44.9 & 0.432 \\
Carcass yield (\%) & 73.7 & 71.0 & 73.1 & 1.6 & 0.139 \\
Breast (\% CCW) & 38.3 & 37.7 & 39.1 & 0.5 & 0.666 \\
Leg (\% CCW) & 13.8 & 13.8 & 13.5 & 0.2 & 0.836 \\
Wing (\% CCW) & 5.1 & 5.2 & 5.1 & 0.1 & 0.247 \\
Back, neck (\% CCW) & 24.1 & 24.5 & 23.6 & 0.4 & \\
\hline
\end{tabular}

$\mathrm{a}, \mathrm{b}-$ mean values with different superscripts within a row differ significantly $(\mathrm{P} \leq 0.05)$.

*Standard error of the means.

Table 6. Effect of different levels of cinnamon oil dietary supplementation on meat quality characteristics of broilers (least square means \pm standard error)

\begin{tabular}{l|c|c|c|c|c}
\hline & \multicolumn{3}{|c|}{$\begin{array}{c}\text { Cinnamon oil supplementation } \\
\text { (ml/kg feed) }\end{array}$} & \multirow{2}{*}{$\begin{array}{c}\text { Pooled } \\
\text { S.E.M.* }\end{array}$} & $\begin{array}{c}\text { Significance } \\
\text { level } \\
\text { (P-value) }\end{array}$ \\
\cline { 2 - 4 } & 0 & 0.5 & 1.0 & & 0.392 \\
\hline $\mathrm{pH}_{24}$ & 5.79 & 5.76 & 5.82 & 0.04 & \\
Colour parameters & & & & & 0.263 \\
$\mathrm{~L}^{*}$ & 43.84 & 43.31 & 42.38 & 0.63 & 0.528 \\
$\mathrm{a}^{*}$ & 5.20 & 5.67 & 5.42 & 0.29 & 0.669 \\
$\mathrm{~b}^{*}$ & 10.00 & 9.89 & 9.62 & 0.30 & 0.508 \\
Intramuscular fat (\%) & 1.34 & 1.38 & 1.33 & 0.03 & 0.675 \\
Cooking loss (\%) & 13.58 & 14.87 & 14.55 & 0.97 & 0.134 \\
Shear force (N/mm $\left.{ }^{2}\right), \log$ & 0.037 & 0.043 & 0.036 & 0.003 & \\
\hline
\end{tabular}

*Standard error of the means.

No significant differences were found among the treatment groups.

Table 7. Effect of refrigerated $\left(\right.$ at $4^{\circ} \mathrm{C}$ ) or long-term frozen $\left(\right.$ at $-20^{\circ} \mathrm{C}$ ) storage period on lipid oxidation (MDA $-\mathrm{ng} / \mathrm{g}$ ) of raw pectoralis major muscle (log values) (least square means \pm standard error)

\begin{tabular}{l|c|c|c|c}
\hline \multirow{2}{*}{ Storage period** } & \multicolumn{2}{|c|}{ Cinnamon oil supplementation (ml/kg feed) } & \multirow{2}{*}{$\begin{array}{c}\text { Pooled } \\
\text { S.E.M.* }\end{array}$} \\
\cline { 2 - 4 } & 0 & 0.5 & 1.0 & \\
\hline (days, at $\left.4^{\circ} \mathrm{C}\right)$ & & & & 0.04 \\
1 & 1.08 & 0.95 & 0.98 & 0.06 \\
6 & 1.42 & 1.35 & 1.27 & 0.07 \\
9 & 1.73 & 1.58 & 1.56 & 0.07 \\
(months, at $\left.-20^{\circ} \mathrm{C}\right)$ & 1.79 & 1.67 & 1.69 & \\
4 & & & & 0.02 \\
5 & 1.48 & 1.48 & 1.41 & 0.09 \\
6 & 1.79 & 1.72 & 1.68 & 0.09 \\
\hline
\end{tabular}

*Standard error of the means.

**Time effect was significant, since oxidation values increased with storage period $(\mathrm{P} \leq 0.001)$ but the interaction of time with treatment was not significant; no effect of cinnamon oil supplementation on MDA values was observed $(\mathrm{P}=0.320)$. Higher levels of MDA indicate higher rates of lipid oxidation. 


\section{Discussion}

\section{Growth performance}

In the present study (Table 2), cinnamon oil supplementation did not have an influence on the BW, FI and FCR of broilers ( $\mathrm{P}>0.05)$. Different levels of cinnamon powder $(250,500,1000$ or $2000 \mathrm{mg} / \mathrm{kg}$ ) (Koochaksaraie et al., 2011) or cinnamon oil (500-1000 ppm) (Ciftci et al., 2009) appear not to have a significant effect on feed intake and growth performance of broilers. Barreto et al. (2008) have reached the same conclusions after the incorporation of a cinnamon extract $(1000 \mathrm{ppm})$ in diet of broilers. Growth performance of broilers was also not significantly influenced after the dietary supplementation with cinnamaldehyde (100 ppm) (Lee et al., 2003). Moreover, no differences in FI and FCR of broilers were found after the dietary incorporation of cinnamon powder (2-4 g/ $\mathrm{kg}$ ) (Toghyani et al., 2011) or an essential oil extract from oregano, cinnamon and pepper (200 ppm) (Hernandez et al., 2004) or a plant extract (100 ppm) (a blend of clove and cinnamon oil) (Isabel and Santos, 2009) in diet of broilers. However, the dietary supplementation with a blend of oregano, cinnamon and pepper essential oil (200 ppm) (Garcia et al., 2007) improved FCR (0-42 days).

The exact reasons for the discrepancies between these studies are speculative but they could have been due to different levels of cinnamon oil supplementation, the variability in the concentration of the major bioactive compounds (cinnamaldehyde, eugenol) among the different parts (barks, leaves, flowers etc) of the plant used, the period of supplementation and the broiler genotype. Moreover, the variability in the efficacy of cinnamon oil on performance of broilers could also be attributed, among others, to the composition of the basal diet, level of feed intake, hygienic standards and environmental conditions. For example, feeds containing highly digestible ingredients limit the proliferation of bacteria in the intestinal tract because no adequate substrate is left for bacterial growth, thereby reducing the antimicrobial potential of plant extracts. Similar results are observed when birds are raised under low immune challenge conditions or strict health control (Brenes and Roura, 2010).

Mortality rates were not significantly different among the treatment groups, as was also demonstrated by Ciftci et al. (2009) in broilers fed a cinnamon oil (500-1000 ppm) supplemented diet. At the same time, no effect on mortality values was observed after the dietary supplementation with a plant extract $(100 \mathrm{mg} / \mathrm{kg})$ consisting of capsaicin, cinnamaldehyde and carvacrol (Jamroz et al., 2005).

\section{Broilers' behaviour}

According to the knowledge of the authors, there is no data concerning the influence of cinnamon oil supplementation on the feeding behaviour of broilers. In the present study, inclusion of cinnamon oil in diet of broilers was not associated with a significant difference in Pf or Pw probabilities, until the age of 17 days (Table 3). These findings are in agreement with the results of FI, since no significant differences were found among the treatment groups (Table 2). On the other hand, Symeon et al. (2010) observed that dietary oregano essential oil supplementation decreased the probability of a bird standing at the feeder or the drinker. Moreover, Lee et al. 
(2003) found that dietary cinnamaldehyde supplementation had a negative effect on water intake.

Significant negative correlations of $\mathrm{Pw}$ with age and time of day were demonstrated. On the other hand, Pf was positively correlated with age but negatively with the time of the day. It can be concluded that the birds decreased their visits to the drinkers, but increased their visits to the feeders from the first to the seventeenth day of recording. The present results are not in accordance with Bokkers and Koene (2003) who observed that age was negatively correlated to the birds' movements and feeding behaviour. A possible explanation is that broilers' behaviour was recorded until the 17th day of age and not between the 21 st and 42 nd day, when the birds grow faster, get heavier, spend more time lying or sitting and visit the feeders less often compared to the first days of their life (Savory and Lariviere, 2000). Moreover, the visits to the feeders and the drinkers became less frequent during the day. It can be concluded that the frequent presence of birds at the feeders in the early morning may be attributed to the increased appetite that follows the resting period when lights are off and is likely to be correlated with the feed stimulus from the daily fill of feeders.

\section{Internal organs (liver, heart, gizzard) and abdominal fat}

The different levels of cinnamon oil supplementation did not influence abdominal fat and internal organs (liver, heart and gizzard) weight (g) among the groups (Table 4). No significant differences in the weights of internal organs have also been found in broilers after the dietary supplementation with cinnamon powder $(2-4 \mathrm{~g} / \mathrm{kg})$ (Toghyani et al., 2011) or cinnamon extract (200 mg/kg) (Barreto et al., 2008) or cinnamaldehyde (100 ppm) (Lee et al., 2003) or an essential oil extract from oregano, cinnamon and pepper (200 ppm) (Hernandez et al., 2004). Moreover, the incorporation of a herbal blend $(10 \mathrm{~g} / \mathrm{kg})$, containing garlic, cinnamon, thyme, rosemary and anise, in diet of broilers did not have an effect on the weight of spleen, bursa of Fabricius, pancreas, gizzard and abdominal fat (Khaligh et al., 2011).

\section{Carcass and meat quality characteristics}

As illustrated in Table 5, cinnamon oil supplementation did not have a significant effect on the evaluated carcass traits (carcass yield, breast, leg, wing, back-neck) of broilers, although the absolute weight of breast (g) was significantly lower in $\mathrm{C} 1$ compared to the other groups (data not shown). Different levels of cinnamon powder $(250,500,1000$ or 2000 ppm) (Koochaksaraie et al., 2011) or cinnamon oil (500, 1000 ppm) (Ciftci et al., 2009) appear not to have a significant effect on the evaluated carcass traits. Furthermore, dietary supplementation with a plant extract based on a blend of clove and cinnamon oil (100 ppm) (Isabel and Santos, 2009) or on a blend of oregano, cinnamon and pepper oil (200 ppm) (Garcia et al., 2007) also seems not to influence carcass weight of broilers. However, breast weight ( $\%$ of carcass) appeared to increase after the incorporation of a plant extract based on a blend of clove and cinnamon oil (100 ppm) (Isabel and Santos, 2009) or a plant extract $(100 \mathrm{mg} / \mathrm{kg}$ ) consisting of capsaicin, cinnamaldehyde and carvacrol (Jamroz et al., 2005) in diet of broilers. 
At the same time, quality characteristics of the pectoralis major muscle $\left(\mathrm{pH}_{24}\right.$, colour parameters, cooking loss and shear force value) were not significantly influenced by the dietary treatment (Table 6). In a previous experiment, sensory evaluation also indicated no changes in meat flavour and odour intensity or desirability after the dietary supplementation with cinnamon powder $(2-4 \mathrm{~g} / \mathrm{kg})$ in broilers (Toghyani et al., 2011).

As presented in Table 7, refrigerated and long-term frozen storage increased the levels of malondialdehyde (MDA), the compound used as an index of lipid oxidation. However, results indicated that incorporation of cinnamon oil into the broilers diets at the levels of 0.5 and $1 \mathrm{ml} / \mathrm{kg}$ did not significantly influence lipid oxidation in the refrigerated and long-term frozen pectoralis major muscle samples, although the MDA values of the cinnamon tended to be lower compared to the control group (Table 7).

Dietary supplementation has been proved to be a simple and convenient strategy to uniformly introduce a natural antioxidant into phospholipid membranes where it may effectively inhibit the oxidative reactions at their localized sites (Lauridsen et al., 1997). Although cinnamon constituents possess intense antioxidant in vitro action and prove beneficial against free radical damage to cell membranes (Dragland et al., 2003), no effects of cinnamon oil supplementation (in vivo) on lipid oxidation rate were observed in the present study. In contrast with the present findings, MDA levels were decreased in blood serum after cinnamon oil supplementation in broilers (250-1000 ppm), possibly due to suppression of lipid peroxidation via the enhancement of hepatic antioxidant enzyme activities (glutathione peroxidise, superoxide dismutase, catalase, gamma-glutamyl transferase etc) (Faix et al., 2009; Ciftci et al., 2010). In detail, cinnamon oil supplementation appears to modify the function of liver, hepatic metabolism and blood glutathione peroxidase activity (Faix et al., 2009). As a result, polyunsaturated fatty acids (PUFAs) and omega-6 fatty acid levels are increased, but saturated fatty acids (SFAs) levels are decreased in the liver (Dalkilic et al., 2009), the serum and the meat (thigh) (Ciftci et al., 2010) of broilers.

In conclusion, no significant differences of dietary cinnamon oil supplementation on meat quality characteristics (colour parameters, $\mathrm{pH}_{24}$, cooking loss, intramuscular fat and shear values) were observed. The extent of lipid oxidation in raw pectoralis major muscle stored at $4^{\circ} \mathrm{C}$ for up to 9 days or at $-20^{\circ} \mathrm{C}$ for up to 6 months was also not influenced by the dietary treatment. No significant differences were also found in internal organ weights and carcass characteristics (apart from breast weight) among the treatment groups. Cinnamon oil supplementation appeared not to affect the final body weight, feed intake and feed conversion ratio. Finally, cinnamon oil supplementation was not associated with a significant difference in the probability of a bird standing at the feeder or the drinker until the age of 17 days. The present results suggest that cinnamon oil at the selected concentrations $(0.5$ and $1 \mathrm{ml} / \mathrm{kg}$ feed $)$ may not have the potential to improve broilers' growth performance, carcass and meat characteristics. However, further experimentation is warranted to elucidate its exact action in broiler metabolism and development. 


\section{References}

B akkali F., Averbeck S., Averbeck D. (2008). Biological effects of essential oils - a review. Food Chem. Toxicol., 46: 446-475.

B aratta M.T., Dorman H.J.D., D e ans S.G., Figue iredo A.C., B arros o J.G., Ruberto G. (1998). Antimicrobial and antioxidant properties of some commercial essential oils. Flavour Frag. J., 13: 235-244.

B arreto M.S.R., Menten J.F.M., Ra c a ni c ci A.M.C., P e re ir a P.W.Z., Rizzo P.V. (2008). Plant extracts used as growth promoters in broilers. Braz. J. Poultry Sci., 10: 109-115.

B o k k e r s E.A.M., K o e n e P. (2003). Behavior of fast and slow growing broilers to 12 weeks of age and the physical consequences. Appl. Anim. Behav. Sci., 81: 59-72.

Botsoglou N.A., Fletouris D.J., Papageorgiou G.E., Vassilopoulos V.N., Mantis A.J., Trakatellis A.G. (1994). A rapid, sensitive and specific thiobarbituric acid method for measuring lipid peroxidation in animal tissues, food and feedstuff samples. J. Agric. Food Chem., 42: 1931-1937.

Brenes A., R oura E. (2010). Essential oils in poultry nutrition: Main effects and modes of action. Anim. Feed Sci. Technol., 158: 1-14.

C a s o n J.A., L y o n C.E., P a p a C.M. (1997). Effect of muscle opposition during rigor on development of broiler breast meat tenderness. Poultry Sci., 76: 785-787.

Ciftc i M., Dalkili c B., Cerci I.H., Guler T., Ertas O.N., Arslan O. (2009). Influence of dietary cinnamon oil supplementation on performance and carcass characteristics in broilers. J. Appl. Anim. Res., 36: 125-128.

C if t c i M., S i m s e k U.G., Yuc e A., Y $11 \mathrm{maz}$ O., D a 1 kil i c B. (2010). Effects of dietary antibiotic and cinnamon oil supplementation on antioxidant enzyme activities, cholesterol levels and fatty acid compositions of serum and meat in broiler chickens. Acta Vet. Brno, 79: 33-40.

D a lk il i c B., C iftc i M., Gule r T., C e r c i I.H., Ertas O.N., Guven c M. (2009). Influence of dietary cinnamon oil supplementation on fatty acid composition of liver and abdominal fat in broiler chicken. J. Appl. Anim. Res., 35: 173-176.

Dragland S., S en o o H., Wake K., Holte K., B lom off R. (2003). Several culinary and medicinal herbs are important sources of dietary antioxidants. J. Nutr., 133: 1286-1290.

En g b e rg R.M., L a urid s e n C., J e n s e n S.K., J a k o b s e n K. (1996). Inclusion of oxidised vegetable oil in diet of broilers. Its influence on nutrient balance and on antioxidative status of broilers. Poultry Sci., 75: 1003-1011.

F a ix S., F a i x o v a Z., P l a c h a I., K o p p e 1 J. (2009). Effect of Cinnamomum zeylanicum essential oil on antioxidative status in broiler chickens. Acta Vet. Brno, 78: 411-417.

F e 11 e n berg M.A., S p e is k y H. (2006). Antioxidants: their effects on broiler oxidative stress and its meat oxidative stability. World Poultry Sci. J., 62: 53-70.

F o l ch J., Le e s M., S t a n ley S.G.H. (1957). A simple method for the isolation and purification of total lipids from animal tissues. J. Biol. Chem., 226: 497-509.

Garcia V., Catala-Gregori P., Hernandez F., Megi as M.D., Madrid J. (2007). Effect of formic acid and plant extracts on growth, nutrient digestibility, intestine mucosa morphology, and meat yield of broilers. J. Appl. Poultry Res., 16: 555-562.

Govaris A., B ot s o g lou N., P a pa g e orgiou G., B ot s o glou E., A m bros i a d is I. (2004). Dietary versus post-mortem use of oregano oil and/or $\alpha$-tocopherol in turkeys to inhibit development of lipid oxidation in meat during refrigerated storage. Int. J. Food Sci. Nutr., 55: 115-123.

Hernandez F., Madrid J., Garcia V., Orengo J., Megi as M.D. (2004). Influence of two plant extracts on broilers performance, digestibility and digestive organ size. Poultry Sci., 83: 169-174.

I s a b e 1 B., S a n t o s Y. (2009). Effects of dietary organic acids and essential oils on growth performance and carcass characteristics of broiler chickens. J. Appl. Poultry Res., 18: 472-476.

Jamroz D., Wiliczki ewicz A., Wertelecki T., Orda J., Skopurinska J. (2005). Use of active substances of plant origin in chicken diets based on maize and locally grown cereals. $\mathrm{Br}$. Poultry Sci., 46: 485-493.

J a y a p ra k a s h a G.K., J a g a $\mathrm{n}$ m o h a n R a o L., S a k a ri a h K.K. (2004). Antioxidant activities of flavidin in different in vitro model systems. Biorg. Med. Chem., 12: 5141-5146. 
Jay a prakasha G.K., Negi P.S., Jena B.S., Jaganmohan Rao L. (2007). Antioxidant and antimutagenic activities of Cinnamomum zeylanicum fruit extracts. J. Food Comp. Anal., 20: $330-336$.

K a n ner J. (1994). Oxidative processes in meat and meat products: Quality implications. Meat Sci., 36: 169-189.

Khaligh F., Sadeghi G., Karimi A., Vaziry A. (2011). Evaluation of different medicinal plants blends in diets for broiler chickens. J. Med. Plants Res., 5: 1971-1977.

K o o cha ks arai e R.R., Ir a n i M., Gharavys i S. (2011). The effects of cinnamon powder feeding on some blood metabolites in broiler chicks. Braz. J. Poultry Sci., 13: 197-201.

La uridsen C., B u ckley D.J., M or ris s e y P.A. (1997). Influence of dietary fat and vitamin E supplementation on $\alpha$-tocopherol levels and fatty acid profiles in chicken muscle membranal fractions and on susceptibility to lipid peroxidation. Meat Sci., 46: 9-22.

Le e K.-W., Everts H., K a p pert H.J., Frehner M., L o s a R., B eynen A.C. (2003). Effects of dietary essential oil components on growth performance, digestive enzymes and lipid metabolism in female broiler chickens. Br. Poultry Sci., 44: 450-457.

Lunn D.J., Thom a s A., B e st N., S p i e g e 1 h a l t e r D. (2000). WinBUGS - A Bayesian modelling framework: concepts, structure, and extensibility. Stat. Comput., 10: 325-337.

Ran a singhe L., J a y a w a r d e na B., A bey w i c kra ma K. (2002). Fungicidal activity of essential oils of Cinnamomum zeylanicum (L.) and Syzygium aromaticum (L.) Merr et L.M.Perry against crown rot and anthracnose pathogens isolated from banana. Lett. Appl. Microbiol., 35: 208-211.

S a vory C.J., L arivi er e J.M. (2000). Effects of qualitative and quantitative food restriction treatments on feeding motivational state and general activity level of growing broiler breeders. Appl. Anim. Behav. Sci., 69: 135-147.

S y m e on G.K., Zint i la s C., D e m ir is N., B i ze lis I.A., D e lig e org is S.G. (2010). Effects of oregano essential oil dietary supplementation on the feeding and drinking behavior as well as the activity of broilers. Int. J. Poultry Sci., 9: 401-405.

Toghyani M., Toghyani M., Gheis ari A., Ghalamkari G., Eghbalsaied S. (2011). Evaluation of cinnamon and garlic as antibiotic growth promoter substitutions on performance, immune responses, serum biochemical and haematological parameters in broiler chicks. Livest. Sci., 138: 167-173.

Received: 22 I 2014

Accepted: 23 IV 2014 